\title{
Uso de resíduos na pavimentação rodoviária
}

\author{
Use of waste in road paving \\ Uso de residuos en la pavimentación de carreteras
}

Recebido: 23/10/2021 | Revisado: 30/10/2021 | Aceito: 01/11/2021 | Publicado: 02/11/2021

\author{
Julierme Siriano da Silva \\ ORCID: https://orcid.org/0000-0002-7262-699X \\ Universidade de Gurupi, Brasil \\ E-mail: julierme_piu@uft.edu.br \\ Monique Gabriela Reis Farias Pimentel \\ ORCID: https://orcid.org/0000-0002-0991-8999 \\ Universidade de Gurupi, Brasil \\ E-mail: monique.gaby06@gmail.com
}

\begin{abstract}
Resumo
A presente pesquisa trabalhará a utilização dos resíduos sólidos na pavimentação rodoviária, considerando que novas metodologias vêm sendo traçadas para oferecer maior eficácia a este processo, e todos os benefícios econômicos e ecológicos provindos do reaproveitamento destes materiais em tais processos. De forma qualitativa fundamentada bibliograficamente, visa responder a seguinte problemática: Como ocorre o reaproveitamento de resíduos na pavimentação rodoviária? Este trabalho tem como objetivo estudar o estado do processo que utiliza resíduos em pavimentação rodoviária, dando enfoque aos métodos utilizados em cada tipo de resíduo, desempenho e suas principais características. Justifica-se o estudo da utilização de resíduos na pavimentação rodoviária tendo em vista a necessidade crescente de utilizar melhor os recursos disponíveis. Portanto, ao se pesquisar esse tema, além de avançar no fator ambiental, pode-se desenvolver a questão econômica, que muitas vezes é um dos aspectos motivacionais muito mais apreciados pelos empresários do ramo da construção.
\end{abstract}

Palavras-chave: Resíduos; Pavimentação; Ecológico; Eficácia; Motivacionais.

\begin{abstract}
This research will work on the use of solid waste in road paving, considering that new methodologies have been drawn up to offer greater efficiency to this process, and all the economic and ecological benefits derived from the reuse of these materials in such processes. In a qualitative way based on bibliography, it aims to answer the following problem: How does the reuse of waste occur on the road pavement? This work aims to study the state of the process that uses waste in road paving, focusing on the methods used in each type of waste, performance and its main characteristics. The study of the use of waste in road paving is justified in view of the growing need to make better use of available resources. Therefore, when researching this topic, in addition to advancing the environmental factor, the economic issue can be developed, which is often one of the motivational aspects much more appreciated by entrepreneurs in the construction industry.
\end{abstract}

Keywords: Waste; Paving; Ecological; Efficiency; Motivational.

\section{Resumen}

Esta investigación trabajará sobre el uso de residuos sólidos en la pavimentación de carreteras, considerando que se han diseñado nuevas metodologías para ofrecer una mayor efectividad a este proceso, y todos los beneficios económicos y ecológicos que se derivan de la reutilización de estos materiales en dichos procesos. De forma bibliográfica de base cualitativa, se pretende dar respuesta al siguiente problema: ¿Cómo es la reutilización de residuos en la pavimentación de carreteras? Este trabajo tiene como objetivo estudiar el estado del proceso que utiliza los residuos en la pavimentación de carreteras, centrándose en los métodos utilizados en cada tipo de residuo, su comportamiento y sus principales características. El estudio del uso de residuos en la pavimentación de carreteras se justifica ante la creciente necesidad de hacer un mejor uso de los recursos disponibles. Por tanto, al investigar este tema, además de avanzar en el factor ambiental, se puede desarrollar el tema económico, que muchas veces es uno de los aspectos motivacionales mucho más apreciados por los emprendedores de la industria de la construcción.

Palabras clave: Residuos; Pavimentación Ecológico; Eficiencia; Motivacional.

\section{Introdução}

A construção de rodovias no Brasil passa por diversas dificuldades devido ao baixo investimento público, principalmente nos últimos anos, há a burocracia e o alto custo na execução das obras, além da alta taxa de deterioração das 
estradas em função do aumento da frota e o excesso de carga transportado dos caminhões, somados à falta de fiscalização (DNIT 2018).

O conhecimento do estado funcional e estrutural das vias permite a intervenção nas suas características visando ampliação de sua vida útil, possibilitando assim, melhorias na malha rodoviária brasileira, de forma simples, reduzindo seus custos com as reconstruções. Tendo como objetivo, determinar o grau de deterioração da via e garantir o conforto do usuário quanto ao rolamento e a condição da superfície

Como citado por John (1997), o estudo da reutilização e da reciclagem de resíduos tornou-se prioritário quanto ao aspecto ambiental. Além disso, o aproveitamento dos resíduos pode apresentar diversos benefícios técnicos, econômicos, energéticos e, é claro, ambientais, como redução do volume de extração de matéria-prima, conservação de matéria-prima não renovável, redução do consumo de energia, menor emissão de poluentes, como o $\mathrm{CO} 2$, e geração de recursos financeiros antes inexistentes.

A presente pesquisa ocorre de forma qualitativa fundamentada bibliograficamente, visa responder a seguinte problemática: Como ocorre o reaproveitamento de resíduos na pavimentação rodoviária? Este trabalho tem como objetivo estudar o estado do processo que utiliza resíduos em pavimentação rodoviária, dando enfoque aos métodos utilizados em cada tipo de resíduo, desempenho e suas principais características.

Justifica-se o estudo da utilização de resíduos na pavimentação rodoviária tendo em vista a necessidade crescente de utilizar melhor os recursos disponíveis. Portanto, ao se pesquisar esse tema, além de avançar no fator ambiental, pode-se desenvolver a questão econômica, que muitas vezes é um dos aspectos motivacionais muito mais apreciados pelos empresários do ramo da construção.

\section{Metodologia}

A pesquisa caracterizou-se como pesquisa bibliográfica e exploratória descritiva e qualitativa, apresentada por meio de análise de discurso e análise de conteúdo. Segundo Gil (2002), a pesquisa bibliográfica é uma metodologia que utiliza materiais já publicados, principalmente compostos por livros, periódicos e atualmente disponíveis na Internet, para fornecer uma base científica para a pesquisa. Este método abordou os principais conceitos e definições de pavimentação de estradas e agregado reciclado, bem como contextualizou o uso de agregado reciclado na pavimentação.

Também é utilizada a pesquisa exploratória que, segundo Ventura (2002), é utilizada para nomear critérios de seleção de dados, amostragem de informações e critérios de análise de processamento de dados. Esse método foi necessário para selecionar os pontos da abordagem da pesquisa, para nomear e sistematizar cada tema discutido, criando um processo de coerência e coerência. Segundo Gil (2002), a pesquisa exploratória é fundamental para abordar temas relevantes para a sociedade. Para que tais dados possam ser comparados e medidos de acordo com os trabalhos pesquisados.

O estudo é característico de estudos descritivos, que, segundo Gil (2002), são estudos cujo objetivo principal é descrever as características de uma determinada população ou fenômeno, ou ainda estabelecer relações entre variáveis. O método descritivo foi fundamental para descrever os conceitos e definições de agregado reciclado e seu uso na pavimentação.

No que diz respeito à metodologia, o projeto busca formas de explicar os resultados da pesquisa qualitativa que, segundo Mazzoti (2006, p. 650), o método qualitativo consiste em testar uma unidade específica, localizada em seu contexto, selecionada. de acordo com - critérios definidos - definidos e a partir de várias fontes de dados, o que sugere uma visão holística do fenômeno estudado. 


\section{Resultados e Discussão}

\subsection{Pavimentação}

A norma ABNT NBR-7207: 1982 especifica que o pavimento é uma estrutura pós-terraplenagem projetada economicamente e como um todo para resistir e distribuir as forças verticais do tráfego sobre o solo a fim de melhorar as condições de rolamento, conforto e segurança, bem como resistência ao as tensões horizontais que o afetam, tornando a superfície de rolamento mais durável (ABNT, 1982)

O pavimento segundo Balbo (2007) é uma estrutura durável, composta por camadas sobrepostas de diversos materiais compactados, adequados para o manejo estrutural e operacional de tráfego, em de forma sustentável e com o mínimo custo possível, tendo em conta os diferentes horizontes de serviços obrigatórios de prevenção, reparação e reabilitação.

Nesse sentido, segundo Balbo (2007), estruturalmente um pavimento deve absorver, clarear e transmitir cargas às camadas inferiores, que geralmente são menos resistentes. Todos os componentes do pavimento devem funcionar com deformações compatíveis com sua natureza e capacidade de carga, ou seja, os materiais que constituem as camadas do pavimento não estão sujeitos a fissuras ou danos prematuros e não intencionais.

A pavimentação segundo Balbo (2007) é uma atividade que consiste na construção de uma estrutura, que tem como principal objetivo melhorar a exploração do trânsito, independentemente da sua natureza, pois cria uma superfície mais regular e aderente, o que permite um maior conforto de viagem e maior segurança em áreas úmidas, respectivamente ou em condições úmidas.

Segundo Horonjeff (1966), os pavimentos rígidos consistem essencialmente em camadas de "cobertura" e "solo". A existência de uma laje de concreto consome praticamente toda a demanda, espalhando-a por uma grande área. Ao atingir o subleito, terreno sobre o qual repousa a passarela, seja de corte ou de aterro, a carga está suficientemente amortecida. Devido à maior rigidez da laje de concreto em relação aos revestimentos betuminosos, as pressões exercidas sobre esta fundação são muito baixas.

Deste modo, quando se trata de resistência, a qualidade exigida não precisa ser tão alta quanto aquela que caracteriza a base (Horonjeff, 1966). De acordo com as notas de aula sobre os conceitos básicos de pavimentação de Greco (2010), no caso de pavimentos rígidos, o coeficiente de amortecimento da camada sobre a qual o pavimento repousa tem uma influência decisiva nas tensões que surgem no concreto sob a influência do cargas de tráfego aplicadas.

O piso flexível é composto por várias camadas que devem trabalhar juntas, cada camada absorve parte da demanda imposta e transfere o restante para a camada inferior. O revestimento consiste em uma mistura de material betuminoso e agregado. A sua principal função é tornar a base impermeável para evitar a penetração da água na superfície e protegê-la da abrasão e dispersão de cargas causadas pelo tráfego. (Horonjeff, 1966).

Ao pavimentar uma área, você deve primeiro analisar que tipo de material de pavimentação produzirá os resultados mais eficazes com base na pesquisa. Analise a área e o ambiente para determinar a resistência que o pavimento deve ter e se ele pode suportar o desgaste ao longo dos anos (Marques, 2012).

A intensidade do tráfego é um fator importante para determinar a resistência do pavimento, como uma rodovia federal (BR) resiste à pressão do tráfego e desgasta mais do que uma rodovia estadual (GO) porque, na fase de construção, a rodovia federal está sujeita a mais tratamento específico, bem como reforços adicionais (Marques, 2012).

O sistema de pavimentação consiste em quatro camadas principais: revestimento asfáltico, base, sub-base e reforço de sub-base. Dependendo do volume de tráfego, do tipo de tráfego, do solo existente e da vida útil do projeto, o revestimento pode ser constituído por uma camada de carga e por camadas intermediárias ou de ligação. Porém, nos casos mais comuns, uma única camada de massa asfáltica é utilizada como revestimento (SPT SONDAGENS, 2012). 
A área da fundação na qual todo o piso será apoiado é chamada de sub-fundação. É extremamente importante examinar e analisar o solo até uma profundidade significativamente afetada pelas cargas de tráfego, 0,60 a 1,50 m de profundidade (Marques, 2012). Armadura de fundação é uma camada integral do pavimento com espessura transversal constante e espessura longitudinal variável, que está relacionada à dimensão do pavimento. A fundação é fortalecida na após sua regularização, e sua função é melhorar sua qualidade e regular a espessura da fundação (Marques, 2012).

Substrato é a camada que completa a base. É utilizado quando não é recomendável fazer a base diretamente no reforço da camada. Normalmente utilizada para ajustar a espessura da base (Marques, 2012). Para uma base muito grossa, com mais de 30 centímetros de espessura, a melhor opção é dividir essa camada em duas partes, formadas por materiais diferentes. A base é chamada de camada superior e o substrato é a camada inferior. Quanto ao comportamento mecânico, ambos só podem atuar na compressão e neste caso existe um piso realmente flexível (Merighi, 2015).

O Esmalte é projetado para suportar as tensões verticais dos veículos, distribuindo-as adequadamente para a camada subjacente, feita na sub-base, sub-base ou reforço do solo, devidamente regulada e compactada. O revestimento será feito nesta camada (Marques, 2012).

Revestimento é a última camada diretamente afetada pelo tráfego e, portanto, a camada mais suscetível à abrasão para sustentá-la. O objetivo é ser o mais impermeável possível, proporcionar boas condições de rolamento para conforto e segurança e resistir a tensões horizontais ativas, tendo uma superfície relativamente durável (Marques, 2012).

\subsection{Elementos da pavimentação}

$\mathrm{O}$ asfalto pode ser definido como uma mistura de hidrocarbonetos de petróleo obtida por destilação ou naturalmente, cujo principal componente é o betume, que também pode conter oxigênio, nitrogênio e enxofre em pequenas proporções. $\mathrm{O}$ betume é uma mistura de hidrocarbonetos pesados com propriedades aglutinantes, inflamáveis e altamente viscosas.

No Brasil, os termos betume e asfalto são frequentemente usados como sinônimos (CNT, 2019). A função primária do asfalto em um pavimento é promover a adesão entre os agregados da mistura e entre esta e a superfície sobre a qual será aplicado, formando uma peça denominada "ligante". Além disso, é responsável por garantir a flexibilidade adequada do pavimento da estrada para que seja resistente ao tráfego e às intempéries, sem deformações ou trincas precoces, que comprometem a durabilidade da infraestrutura (CNT, 2019).

No Brasil, o asfalto é utilizado em mais de $99 \%$ dos trechos pavimentados (CNT, 2019). Essa contribuição tem um custo elevado, aumentando os custos de construção e manutenção de estradas. Além disso, calçadas deformadas e danificadas contribuem para o desgaste dos veículos, aumentando o consumo de combustível e o tempo de deslocamento, gerando prejuízos para quem utiliza as rodovias e a economia do país.

Atualmente, o CAP integra materiais como pneus e borrachas do processo produtivo de calçados industriais. Com o objetivo de melhorar as propriedades mecânicas das misturas asfálticas, bem como reduzir as cargas ambientais decorrentes do crescimento inadequado de sedimentos na natureza, muitos países desenvolveram uma tecnologia para introdução de borracha em revestimentos asfálticos (Gómez-Pablo, 2017).

O betume é obtido pela destilação de certos tipos de óleo, dos quais frações leves (gasolina, diesel e querosene) são removidas no processo de refino. O produto resultante desse processo passou a ser conhecido como Asfalto (CAP). São semissólidos à temperatura ambiente e precisam ser aquecidos para obter a consistência desejada para o uso.

O CAP consiste em 90 a 95\% de hidrocarbonetos e 5 a 10\% de heteroátomos (oxigênio, enxofre, nitrogênio e metais vanádio, níquel, ferro, magnésio e cálcio) ligados por ligações covalentes. Todas as propriedades físicas do betume estão relacionadas à sua temperatura. $\mathrm{O}$ modelo estrutural de um ligante como uma dispersão de moléculas polares em um meio apolar ajuda a entender o efeito da temperatura nos ligantes de asfalto. 
De acordo com Bernucci et. al (2007) em temperaturas muito baixas as moléculas são incapazes de se mover em relação umas às outras e a viscosidade é muito alta, nesta situação, o fichário se comporta quase como um sólido. Conforme a temperatura sobe, algumas moléculas começam a se mover e pode até haver um fluxo entre as moléculas. O aumento do movimento diminui a viscosidade e o aglutinante se comporta como um líquido em altas temperaturas. Essa transição é reversível.

Um dos critérios mais utilizados para classificar ligantes é a avaliação de sua susceptibilidade térmica por meio de um determinado teste que mede direta ou indiretamente sua consistência ou viscosidade em diferentes temperaturas. Assim, todos os testes realizados para medir as propriedades físicas dos ligantes asfálticos estão em uma temperatura específica, e alguns também determinam o tempo e a velocidade de carregamento, pois o asfalto é um material termoelástico (Bernucci, et. Al., 2007).

$\mathrm{O}$ asfalto convencional tem um bom desempenho na maioria das aplicações em estradas, atendendo aos requisitos para o desempenho adequado em estradas e condições climáticas. Porém, em condições de aumento de volume e peso por eixo, como em aeroportos, e em caso de condições desfavoráveis de temperatura, é cada vez mais necessário o uso de modificadores de propriedades do asfalto, como polímeros que melhoram as propriedades do ligante (Bernucci et al, 2007).

De acordo com Nakamura (2011), a mistura asfáltica tratada quente pode ser utilizada em revestimentos de baixo volume e alto tráfego, atendendo aos requisitos em ambos os casos. Essas misturas podem ser divididas em termos de classificação de agregados e cargas. O concreto asfáltico denso tem uma curva de tamanho de grão contínua e bem ordenada para dar uma composição um tanto oca.

O concreto asfáltico de alta densidade é a mistura asfáltica tratada a quente mais utilizada no Brasil. Suas propriedades, entretanto, são muito sensíveis à variabilidade do teor de ligante asfáltico, o excesso ou a falta de ligante podem causar problemas com deformação permanente e perda de resistência, levando a deformações e trincas (Nakamura, 2011).

A mistura em escala aberta tem uma curva de tamanho de partícula uniforme e contém agregados de tamanho padrão. Ao contrário do concreto asfáltico, eles retêm uma grande porcentagem de vazios de ar devido a uma pequena quantidade de aglutinante de asfalto e enchimento fino.

O resultado é um revestimento de drenagem que permite que a água penetre no chão. A mistura asfáltica de drenagem pertence a esta categoria, que é conhecida no Brasil como camada de fricção porosa (CPA), e é comumente utilizada como camada rolante nos casos em que o objetivo é aumentar a aderência do pneu na estrada sob a rodovia (Nakamura, 2011).

\subsection{Uso de resíduos na pavimentação rodoviária}

Areias, pedregulhos, rochas e outros elementos artificiais são considerados agregados, geralmente são elementos inertes. Quando usados para criar camadas de subsolo e subleito, consistem em solo, cascalho, escória de alto-forno ou uma mistura desses materiais (Bernucci et al., 2008; Brasil, 2006).

Os agregados confotme Bernucci et al. (2008) usados em pavimentos asfálticos devem ter propriedades que suportem as tensões do pavimento. Os autores também mencionam que as propriedades funcionais deste agregado estão diretamente relacionadas à forma como são unidos, neste sentido, a importância do ligante asfáltico é enfatizada. Portanto, a camada de base e a subestrutura devem ter esta propriedade, com granularidade homogênea, essas camadas serão flexíveis, estabilizadas pela compactação de um material ou composição de material de granularidade adequada, com indicadores geotécnicos precisos conforme especificado (Brasil, 2006).

A classificação de resíduos sólidos de acordo com a NBR 10.004 - ABNT (2004a), determina a existência de uma relação entre a composição dos resíduos e as listas de resíduos e substâncias cujos impactos à saúde e ao meio ambiente são conhecidos. Esta norma divide os resíduos em dois grupos: a) Resíduos Classe I: perigosos; b) Resíduos Classe II: não perigosos; A Classe II é dividida em dois subgrupos: Resíduos da Classe IIA: Não neutros; Resíduos da classe IIB: neutros. 
A composição dos resíduos de construção varia muito de local para local, dependendo da especificidade de cada região, cultura, técnicas de construção e matérias-primas disponíveis. No Brasil, segundo Grubby (2009), a maior parte desses resíduos é composta por materiais inertes e recicláveis como argamassa, concreto, agregado de pedra e cerâmica.

A utilização de agregados reciclados de resíduos de construção na camada de base e na subestrutura do piso, segundo Carneiro et al. (2001), foi um dos caminhos mais difundidos para a sua conclusão por apresentar inúmeras vantagens tanto do ponto de vista econômico quanto ambiental.

Segundo Triches e Kryckyj (1999), do ponto de vista técnico, a utilização de agregados reciclados é uma ótima opção para pavimentação por se tratar de um material não plástico. Nesta perspectiva, pode ser usado em locais onde haja água; é um material com pouca ou nenhuma expansão, ideal para a camada de base e subestrutura, além disso, é um material que pode ser utilizado para reduzir a plasticidade do solo.

Resíduos de pneus são um conhecido problema ambiental que, pela sua natureza (tamanho, forma e composição físicoquímica), não está sujeito à coleta convencional, considerada como resíduo especial (Lund, 2001, apud Fontes, 2009). A grande quantidade de resíduos gerados pela indústria da borracha está motivando mais pesquisas sobre a reciclagem e o reaproveitamento desse material (Specht, 2004).

Specht (2004) também menciona uma grande quantidade de pesquisas sobre a adição desses materiais ao aglutinante de asfalto e os benefícios resultantes, como, por exemplo, aumento da ductilidade, melhor adesão entre o aglutinante e o agregado, resistência às intempéries. Assim, a adição de borracha de pneus usados no asfalto para formar misturas asfálticas contribui para o aproveitamento final adequado desse resíduo sólido (Thives et al., 2013).

Ao introduzir grânulos de borracha de pneu na mistura asfáltica, esta adquire novas propriedades, criando assim o chamado asfalto borracha, além do fator ecológico, a adição de borracha de pneu ao asfalto tem como objetivo melhorar o ligante em termos de suscetibilidade térmica e ductilidade (Fontes, 2009). Ou seja, a utilização desse resíduo em cimento asfáltico ou em misturas modificadas é melhorar as propriedades dos materiais de pavimentação (Specht, 2004).

Então, a superfície é melhorada devido à adição deste modificador, o que torna esta aplicação tecnicamente atrativa. pavimentos (David, 2006). O objetivo deste método é reduzir o consumo de materiais para a construção de uma superfície reciclada.

Segundo Silva (2011), a renovação por reciclagem é caracterizada pelo reaproveitamento total ou parcial de uma camada existente, constituindo uma nova mistura homogênea no processo de mistura e adição de novos materiais, a fim de reaplicar uma camada destinada a tolerar diferentes condições ambientais. além de apoiar os esforços do movimento. $\mathrm{O}$ reaproveitamento de resíduos de construção está claramente associado à redução do impacto ambiental por destinação inadequada, bem como à redução do uso de matéria-prima de origem natural (Bagatini, 2011).

Segundo Mota (2014), o aproveitamento de resíduos classe A na pavimentação é a forma mais fácil e antiga de reciclagem no Brasil. Utiliza entulho como material para a preparação do substrato, fundação e revestimento primário do piso, feito na forma de brita ou mistura de resíduos com solo. Suas vantagens são: menor uso de tecnologia e custos de processo; aproveitamento de todos os componentes minerais do entulho; maior aproveitamento do entulho produzido.

Bagatini, F (2016) diz que, como solução de disposição final, esses materiais descartados podem ser incorporados a agregados utilizados no subsolo e na subestrutura de estradas pavimentadas e devem, obrigatoriamente, passar pelo processo seletivo prévio para não misturar materiais considerados de qualidade inferior, que pode afetar a viabilidade e o piso de excelente desempenho. 


\subsection{Discussão}

Segundo Carneiro et al (2001), o uso de agregados reciclados da construção civil no asfalto e sub-base traz muitos benefícios econômicos, sociais e ambientais. $\mathrm{O}$ uso de agregados para a produção de componentes utilizados na pavimentação tem aumentado nos últimos anos e, embora as pesquisas realizadas indiquem um alto potencial de utilidade, seu uso é relativamente baixo, pois os agregados reciclados são caracterizados por alta variabilidade de composição (Silva et al. 2015).

Em relação à resistência à compressão do concreto com agregado reciclado, Curvo (2014) afirma que a troca do agregado natural por agregado reciclado aumenta a porosidade da mistura, e a resistência do concreto é inferior à resistência convencional.

No entanto, alguns recursos são importantes e podem compensar esse fator. Realizando sua pesquisa, o autor de Ângulo (2005) analisou a composição química e mineralógica de RCDs reciclados e constatou que, para uma dada relação água/cimento, a porosidade dos agregados de RCD recuperados controla o comportamento mecânico do concreto. Os agregados analisados pelo autor apontaram que a porosidade das amostras e o comportamento mecânico do concreto estão relacionados ao teor de ligantes e cerâmicas vermelhas da amostra, visto que constituem um grupo de materiais porosos presentes no agregado.

No campo da proteção ambiental, pude constatar que o interesse em reciclar e reaproveitar resíduos sólidos de construção e demolição (RCD) é cada vez maior, pois é notável o quanto esses resíduos são prejudiciais à natureza, mesmo que sejam descartados nos locais certos, pois pode contaminar o solo e causar graves efeitos ambientais.

Segundo Addis (2010), a sociedade exige padrões de vida cada vez mais elevados e, por isso, exige novas construções e renovações dos edifícios existentes, o que tem um impacto negativo no ambiente. Esse impacto pode ser sentido de várias maneiras: esgotamento dos recursos naturais não renováveis, poluição do ar e degradação da paisagem natural.

Com relação ao uso de agregados reciclados no pavimento de concreto, é possível concluir que os estudos realizados pelos autores do estudo mostram resultados significativos na utilização desses componentes em um pavimento rígido. O desempenho do concreto depende da porcentagem de RCD adicionado à mistura.

O estudo de viabilidade desse material deve ser testado em conjunto com os requisitos de resistência e desempenho do concreto e a questão ambiental, pois quanto mais resíduos forem utilizados na produção do pavimento, menor será o impacto ambiental. As pesquisas realizadas explicam a importância do controle tecnológico do RCD, pois esses materiais são altamente heterogêneos em termos de granulometria e composição físico-química.

Curvo (2014) em sua pesquisa mostra que os RCDs possuem grande potencial para uso como agregado de concreto utilizado em pavimentos rígidos. Além disso, ele percebeu durante esses testes que a maioria dos estudos de caracterização de agregados reciclados atende aos requisitos das normas aplicáveis.

Os resultados deste trabalho também mostram que a utilização de materiais diferentes dos convencionais resulta em um comportamento mecânico diferente da estrutura. Mudar o material requer uma análise aprofundada para garantir que ele seja construído corretamente para a carga. Além disso, a escolha do tipo de resíduo também acarreta um custo que será gerado na concepção e execução da estrutura, tanto do ponto de vista logístico como ambiental. Portanto, é necessária pesquisa não apenas sobre qual material funciona bem, mas também sobre qual é o mais economicamente viável

A utilização deste tipo de agregado é tecnicamente viável, não só pelas propriedades que apresenta, mas também do ponto de vista económico, ambiental e social, visto que a sua utilização reduz significativamente o custo deste tipo de obra e zela pelo ambiente, inúmeros benefícios decorrentes da redução da exploração de agregados naturais de depósitos minerais e seu uso adequado, que na maioria das vezes são lançados em aterros e depósitos, poluindo o meio ambiente.

Como o Brasil é um país onde grande parte do sistema viário ainda não está pavimentado e considerando todos os benefícios do uso de agregados de concreto recuperado, seu uso ainda deve ser incentivado, visto que mesmo com inúmeras possibilidades de aplicação e com alguns avanços em termos de normas, é o uso ainda não é generalizado. 


\section{Considerações Finais}

O uso de agregado reciclado em camadas de pavimentação urbana tem sido uma das formas mais regulares de reaproveitamento. $\mathrm{O}$ uso desse material na pavimentação tem como vantagens o aproveitamento de quantidades significativas de material reciclado, de pequeno e grande porte, pois facilita os processos de pavimentação e a produção do agregado reciclado.

A aplicação correta desses resíduos traz benefícios em todas as áreas, visto que além do aproveitamento final adequado dos resíduos, o pavimento também é de qualidade superior ao convencional. Tendo em vista os fatores ecológicos, econômicos e os próprios benefícios no processo de pavimentação ocasionada pela utilização destes resíduos sólidos torna-se muito importante que os profissionais da área passem a atuarem de forma mais efetiva junto a estas.

Neste sentido, o presente trabalho cumpriu com o objetivo proposto de demonstrar como os resíduos sólidos vem sendo utilizados na pavimentação rodoviária, possuindo diversos benefícios tanto para tal finalidade quanto em relação a dar uma finalidade a estes materiais. Entretanto, faz-se necessário, desta forma, o desenvolvimento de pesquisas que busquem a aplicação desses resíduos de forma mais adequada, buscando a melhor relação custo-benefício, bem como a característica adequada.

\section{Referências}

Alves-Mazzotti, A. J. (2006). Usos e abusos dos estudos de caso. Cadernos de pesquisa, 36, 637-651.

Angulo, S. C., \& Figueiredo, A. D. (2011). Concreto com agregados reciclados. ISAIA, GC Concreto: ciência e tecnologia. Arte Interativa.

Bagatini, F. (2011). Resíduos de construção civil: aproveitamento como base e sub-base na pavimentação de vias urbanas.

Balbo, J. T. (2015). Pavimentação asfáltica: materiais, projeto e restauração. Oficina de Textos.

Bernucci, L. B., da Motta, L. M. G., Ceratti, J. A. P., \& Soares, J. B. (2006). Pavimentação asfáltica: Formação básica para engenheiros. 504 p. Petrobras: Abeda, Rio de Janeiro, RJ. DOI, 10(2.1), 4361-5684.

Bernucci, L. B., Motta, L. D., Ceratti, J. A. P., \& Soares, J. B. (2008). Pavimentação asfáltica: formação básica para engenheiros. $504,27$.

de Pavimentação, D. M. (2006). Departamento Nacional de Infraestrutura de Transportes. Diretoria de Planejamento e Pesquisa. Coordenação Geral de Estudos e Pesquisa. Instituto de Pesquisas Rodoviárias.

Carneiro, A. P., Burgos, P. C., \& Alberte, E. P. V. (2001). Uso do agregado reciclado em camadas de base e sub-base de pavimentos. Projeto Entulho Bom. Salvador: EDUFBA/Caixa Econômica Federal, 190-227.

Carneiro, A. P., Brum, I. A. S., \& Cassa, J. D. S. (2001). Reciclagem de entulho para a produção de materiais de construção-Projeto Entulho Bom. Salvador: EDUFBA.

Curvo, F. D. O. (2014). Estudo da viabilidade técnica/econômica da utilização de RCD como agregados aplicados a pavimentos rígidos. Brasília: CUB

David, D. D. (2006). Misturas asfálticas recicladas a frio: estudo em laboratório utilizando emulsão e agente de reciclagem emulsionado.

Departamento nacional de infraestrutura de transportes. Sistema Nacional de Viação. (2017). http://www.dnit.gov.br/sistema-nacional-de-viacao/sistemanacionaldeviacao

Padilha, L. T. (2015). Avaliação da Tolerância de Peso Permitida Por Eixo no Dimensionamento de Pavimentos Flexíveis.

Gil, A. C. (2002). Como elaborar projetos de pesquisa. 4, 175. Atlas.

Gómez-Pablo, F. G. (2017). Práticas sustentáveis nos pavimentos e sua possível aplicação no mercado brasileiro: Presente e futuro. Monografia (Graduação em Engenharia Civil), Escola Politécnica da Universidade Federal do Rio de Janeiro.

Grubba, D. C. R. P. (2009). Estudo do comportamento mecânico de um agregado reciclado de concreto para utilização na construção rodoviária (Doctoral dissertation, Universidade de São Paulo).

Horonjeff, R. (1966). Aeroportos: planejamento e projeto. Agência Norte-Americana para o Desenvolvimento Internacional USAID.

Impactos da qualidade do asfalto sobre o transporte rodoviário (2019). Brasília, 75p. https://www.cnt.org.br/home

Reciclagem de resíduos da construção (2012). Juiz de Fora. http://www.ufjf.br/pavimentacao/files/2012/0 3/Notas-de-Aula-Prof.-Geraldo.pdf

NAKAMURA, J. (2011). Pavimentação asfáltica: Os tipos de revestimento, o maquinário necessário e os cuidados na contratação, projeto e execução. Infraestrutura urbana: projetos, custos e construção, São Paulo, ano, 2. 
Research, Society and Development, v. 10, n. 14, e310101422179, 2021

(CC BY 4.0) | ISSN 2525-3409 | DOI: http://dx.doi.org/10.33448/rsd-v10i14.22179

Silva, A. H. M. D. (2011). Avaliação do comportamento de pavimentos com camada reciclada de revestimentos asfálticos a frio com emulsão modificada por polímero (Doctoral dissertation, Universidade de São Paulo).

Specht, L. P. (2004). Avaliação de misturas asfálticas com incorporação de borracha reciclada de pneus.

Sondagem prospecção e tecnologia. http://sptsondagem.com.br/

Técnicas, N., \& no Brasil, I. (1999). ABNT-Associação Brasileira de Normas Técnicas. Cabo.

Thives, L. P., Trichês, G., Pereira, P. A., \& Pais, J. C. (2011). Influência do tipo de asfalto base no Desempenho mecânico de misturas com asfalto Borracha.

Trichês, G., \& Kryckyj, P. R. (1999). Aproveitamento de entulho da construção civil na pavimentação urbana. In Congresso Brasileiro de Geotecnia Ambiental, São José dos Campos.

Ventura, P. C. S. (2011). Por uma pedagogia de projetos: uma síntese introdutória. Educação \& Tecnologia, 7(1). 